\title{
A RETROSPECTIVE STUDY OF ESWL IN URINARY LITHIASIS WITH AND WITHOUT STENTING
}

\author{
Ranjan Kumar Dey ${ }^{1}$, Sumantra Dey²
}

${ }_{1}^{1}$ Associate Professor, Department of Urology, RG Kar Medical College and Hospital, Kolkata.

2Junior Resident, Department of Urology, RG Kar Medical College and Hospital, Kolkata.

\section{ABSTRACT}

\section{BACKGROUND}

Urolithiasis is the most common urological disease with a prevalence rate of $10 \%$ - 15\%. Most patients harbouring "simple" renal calculi (less than $2 \mathrm{~cm}$ ) can be treated satisfactorily with ESWL (Extracorporeal shock wave lithotripsy). The insertion of Double J (DJ) stents during ESWL of renal calculi is controversial.

This study aims to understand the necessity and also "pros and cons" of DJ stenting during ESWL procedures.

\section{MATERIALS AND METHODS}

The retrospective observational study was conducted at the Department of Urosurgery, RG Kar Medical College and Hospital, Kolkata. 162 patients had undergone ESWL for renal stone in the Department of Urosurgery during the study period, that is Feb 2013 to Dec 2014. Detailed documentation of clinical profile of patients as well as their radiological reports from records were put in two groups. Group A consisted of patients who underwent no stenting or those who underwent prior stenting one week before which was removed at procedure. Group B consisted of patients who underwent stenting during the procedure with removal after 6 weeks. Records as present regarding infection, blockage, encrustation and migration were documented till six weeks follow-up visit. Stone clearance and complication rates were calculated in the groups.

\section{RESULTS}

Though stone clearance rates were similar in stented and non-stented groups, urinary tract infection was significantly more in the group where stent was retained for six weeks after ESWL.

\section{CONCLUSION}

Therefore, in the debate of ESWL with or without stent urinary tract infection appears to be a major disadvantage, thus limiting stent use to specific situations.

\section{KEYWORDS}

Urinary Lithiasis, Double J Stent, ESWL.

HOW TO CITE THIS ARTICLE: Dey RK, Dey S. A retrospective study of ESWL in urinary lithiasis with and without stenting. J. Evolution Med. Dent. Sci. 2017;6(94):6812-6814, DOI: 10.14260/jemds/2017/1475

\section{BACKGROUND}

Urolithiasis is the most common urological disease with a prevalence rate of $10 \%-15 \% .^{1}$ In eastern region of India, prevalence of stone disease varies from $7 \%-9 \% .^{2}$ The most common component of urinary calculi is calcium, which is a major constituent of nearly $75 \%$ of stones. Calcium oxalate makes up about $60 \%$ of all stones; mixed calcium oxalate and hydroxyapatite $20 \%$ and brushite stones $2 \%$. Both uric acid and struvite (magnesium ammonium phosphate) stones occur approximately $10 \%$ of the time, whereas cystine stones are rare $(1 \%)$.

The primary goal of surgical stone management is to achieve maximal stone clearance with minimal morbidity to the patient. Minimally invasive surgical techniques for the treatment of patients suffering from urinary lithiasis include ureteroscopic removal of stone, percutaneous nephrolithotomy (PNL) and extracorporeal shockwave

'Financial or Other Competing Interest': None.

Submission 03-11-2017, Peer Review 27-11-2017,

Acceptance 04-12-2017, Published 18-12-2017.

Corresponding Author:

Dr. Sumantra Dey,

Flat 8b, 10 Gurusaday Road,

Ajanta Apartments,

Kolkata- 700019.

E-mail: ranjandeyurologist@gmail.com

DOI: $10.14260 /$ jemds $/ 2017 / 1475$ lithotripsy (SWL). Most patients harbouring "simple" renal calculi (less than $2 \mathrm{~cm}$ ) can be treated satisfactorily with SWL. ${ }^{3}$ Factors associated with stone clearance rates after SWL include size of renal calculi, stones within dependent or obstructed portions of the collecting system, stones of certain composition (cystine, calcium oxalate monohydrate and brushite), and obesity or a body habitus that inhibits imaging and targeting of the stone.

The insertion of Double J (DJ) stents during ESWL of renal calculi is controversial. The old rationale was the use of ureteral stents reduces complications after extracorporeal shockwave lithotripsy (ESWL) and contributes to successful stone passage. However, some reports noted complications that are attributed to indwelling ureteral stents and concluded that ureteral stents do not reduce post-SWL complications and they are clearly associated with morbidity and do not improve stone passage markedly.

Insertion and retaining of DJ stent during ESWL procedure makes fragmentation inferior due to loss of stone urine interface and localisation and targeting become difficult. DJ stent itself hinder the clearance of stone by mechanical obstruction. But in certain situation, DJ stent is put in prior to ESWL, as in obstructed system stone size more than $2 \mathrm{~cm} .{ }^{4}$ This study aims to understand the necessity and also "pros and cons" of DJ stenting during ESWL procedures. 


\section{MATERIALS AND METHODS}

This retrospective observational study was conducted at the Department of Urosurgery, RG Kar Medical College and Hospital, Kolkata. 162 patients had undergone ESWL for renal stone in the Department of Urosurgery during the study period, that is Feb. 2013 to Dec. 2014. Data was collected from the case records of these patients regarding timing of stent introduction and removal, outcome of ESWL and occurrence of complications. The patients were followed up for complications, chiefly blockage, encrustation, breakage, infection and migration till the stents were removed. All patients with renal stone between $5 \mathrm{~mm}$ to $20 \mathrm{~mm}$ had been selected for ESWL as per departmental protocol. Exclusion criteria used were elevated serum creatinine $(>1.5 \mathrm{mg} / \mathrm{dL})$, persistent urinary tract infection (UTI), hydronephrosis, hypotension, coagulopathy, severe obesity, pregnancy, urinary congenital anomalies, severe skeletal malformation, aortic or renal artery aneurysm.

All patients with renal stones who fulfilled inclusion and exclusion criteria as defined above were selected for ESWL.

Detailed documentation of clinical and risk factor profile of patients as well as their radiological reports were recorded in two groups. Group A consisted of patients who underwent no stenting (A1) and those who underwent prior stenting one week before, which was removed at procedure (A2). Group B consisted of patients who underwent stenting during the procedure with removal after 6 weeks. Parameters studied were Age, Sex, BMI etc. of patients, stone characteristic like stone density (HFU), stone location, stone size, the frequency of significant painful episode after ESWL with or without DJ stent was noted. Significant painful episode was defined as the one which requires intake of analgesics for its relief. Findings of CT Urography or NCCT KUB, or IVU if it had been done were noted. Details of intraprocedure findings and follow-up after two weeks with x-ray KUB/ USG KUB was recorded. Further records as present regarding infection, blockage, encrustation and migration were documented till six weeks follow-up visit.

Using Fisher's exact ' $\mathrm{T}$ ' test, stone clearance rates were compared in the different groups. Similarly, urinary tract infection rates were compared. The collected data was analysed using statistical methods in Prism 5 software.

\section{RESULTS}

Out of 102 (Group A) patients who did not receive stents after the ESWL, 82 achieved clearance. Among the 60 patients (Group B) who had post ESWL stenting, 44 achieved clearance. There was no statistically significant difference in clearance rate (Table 1).

Group A patients were then categorised as those receiving stenting for one week prior to ESWL, which was removed at the procedure (Group A1), and those who received no stenting at all (Group A2). Here, Group A1 showed clearance of 27 out of 34 patients and Group A2 showed clearance of 55 out of 68 patients. There was no significant difference in clearance (Table 2).

Out of 102 patients who received no stent or stenting prior to procedure, 7 patients had post procedure UTI. On the other hand, out of 60 patients who received stenting at procedure 17 had UTI episodes. So presence of post procedure stent showed a relative risk of $0.42 \quad(95 \%$ confidence interval $0.22-0.79$ ) with $p$ value of 0.004 which is statistically significant (Table 3 ).

\begin{tabular}{|c|c|c|c|}
\hline & $\begin{array}{c}\text { Group A } \\
\text { (A1+A2) } \\
(\%)\end{array}$ & $\begin{array}{c}\text { Group B } \\
\text { (\%) }\end{array}$ & $\begin{array}{c}\text { Total } \\
\text { (\%) }\end{array}$ \\
\hline Clearance & $82(51.6)$ & $44(27.5)$ & $126(77.7)$ \\
\hline No Clearance & $20(12.3)$ & $16(9.9)$ & $36(22.3)$ \\
\hline Total & $\mathbf{1 0 2}(\mathbf{6 2 . 9 )}$ & $\mathbf{6 0}(\mathbf{3 7 . 1 )}$ & $\mathbf{1 6 2}(\mathbf{1 0 0 )})$ \\
\hline \multicolumn{2}{|c|}{ Table 1. Showing Stone Clearance in Group A } \\
(Not Stented and Pre-Stented Patients) and Group B \\
(Patients with Post ESWL Stenting for 6 Wks.)
\end{tabular}

\begin{tabular}{|c|c|c|c|}
\hline & $\begin{array}{c}\text { Group A1 } \\
\text { (\%) }\end{array}$ & $\begin{array}{c}\text { Group A2 } \\
\text { (\%) }\end{array}$ & $\begin{array}{c}\text { Total } \\
\text { (\%) }\end{array}$ \\
\hline Clearance & $27(26.4)$ & $55(53.2)$ & $82(80.4)$ \\
\hline No Clearance & $7(6.9)$ & $13(12.7)$ & $20(19.6)$ \\
\hline Total & $\mathbf{3 4}(\mathbf{3 3 . 3 )}$ & $\mathbf{6 8}(\mathbf{6 6 . 7 )}$ & $\mathbf{1 0 2}(100)$ \\
\hline \multicolumn{2}{|c|}{ Table 2. Showing Stone Clearance in Group A1 } \\
(Patients Stented one week prior with removal of Stent at \\
ESWL Procedure) and Group A2 (Patients who did not receive \\
Stents at all) \\
\hline
\end{tabular}

\begin{tabular}{|c|c|c|c|}
\hline & $\begin{array}{c}\text { Group A } \\
(\mathbf{A 1 + A 2 )}(\%)\end{array}$ & $\begin{array}{c}\text { Group B } \\
(\%)\end{array}$ & $\begin{array}{c}\text { Total } \\
(\%)\end{array}$ \\
\hline Infection & $7(4.3)$ & $17(10.5)$ & $24(14.8)$ \\
\hline No Infection & $95(58.6)$ & $43(26.5)$ & $138(85.2)$ \\
\hline Total & $\mathbf{1 0 2}(62.9)$ & $\mathbf{6 0}(37.1)$ & $\mathbf{1 6 2}(100)$ \\
\hline Table 3. Showing Number of Urinary Tract Infection in \\
Group A (Not Stented and Pre-Stented Patients) and Group \\
B (Patients with Post ESWL Stenting for 6 Wks.) \\
\hline
\end{tabular}

\section{DISCUSSION}

In our study, no significant difference was found in stone clearance between ESWL with or without post procedure DJ stenting. A study conducted in Turkey with 32 patients by Mustafa and Ali-El-Dien also came to the same conclusion. ${ }^{5} \mathrm{~A}$ study conducted on paediatric population however used DJ stents for the stones larger than $13 \mathrm{~mm}$ and found this prevented steinstrasse. ${ }^{6}$ In the stented patients, the clearance rates were not significantly different between those stented one week prior to ESWL and those stented after the ESWL procedure in this study. Extensive search in literature did not reveal any studies where stenting had been done for a period prior to the ESWL procedure.

Complications such as encrustation, blockage, breakage and migration were problems attributable to the stent itself, and were compared only in the pre-ESWL and post-ESWL stented groups. Here, the patients who had pre-ESWL stenting which was removed at the procedure had none of the complications except encrustation in less than $2 \%$ patients compared to $77 \%$ in the post-ESWL stented patients. Blockage, migration and breakage were present only in the post ESWL stented group at rates of $11 \%, 6 \%$ and $3 \%$ respectively.

Urinary tract infection rates were compared between those who received no stent or stent removed prior to ESWL procedure, and those patients in whom stents were retained for 6 weeks post procedure. Here, it was seen that presence of post procedure stent showed a relative risk of 0.42 , which was statistically significant. 


\section{CONCLUSION}

Thus, in the debate of ESWL with or without stent urinary tract infection appears to be a major disadvantage, thus limiting stent use to specific situations like obstructed system, large stone or solitary kidney. ${ }^{7}$

\section{REFERENCES}

[1] Lopez M, Hoppe B. History, epidemiology and regional diversities of urolithiasis. Pediatr Nephrol 2010;25(1):49-59.

[2] Singh PP, Singh LB, Prasad SN, et al. Urolithiasis in Manipur (north eastern region of India). Incidence and chemical composition of stones. Am J Clin Nutr 1978;31(9):1519-25.

[3] Norlin A, Lindell B, Granberg PO, et al. Urolithiasis: a study of its frequency. Scand J Urol Nephrol 1976;10(2):150-3.
[4] Ghoneim IA, El-Ghoneimy MN, El-Naggar AE, et al. Extracorporeal shock wave lithotripsy in impacted upper ureteral stones: a prospective randomized comparison between stented and non-stented techniques. Urology 2010;75(1):45-50.

[5] Mustafa M, Ali-El-Dien B. Stenting in extracorporeal shockwave lithotripsy may enhance the passage of fragments. J Pak Med Assoc 2009;59(3):141-3.

[6] Rostami MY, Taghipour-Gorgikolai M, Sharifian R. Treatment of kidney stones using extracorporeal shock wave lithotripsy (ESWL) and double-J stent in infants. Advances in Urology Article ID 589038, 2012;2012:4.

[7] Kirkali Z, Esen AA, Akan G. Place of double-J stents in extracorporeal shock wave lithotripsy. Eur Urol 1993;23(4):460-2. 